\title{
Identifying key ethical debates for autonomous robots in agri-food: a research agenda
}

\author{
Mark Ryan $^{1} \mathbb{D} \cdot$ Simone van der Burg ${ }^{1} \cdot$ Marc-Jeroen Bogaardt $^{1}$
}

Received: 24 July 2021 / Accepted: 21 September 2021 / Published online: 4 October 2021

(c) The Author(s) 2021

\begin{abstract}
Agribusinesses are investing in different forms of AI robots, as there is a lot of hope that these machines will help meet the challenges within the agricultural industry, which is to efficiently produce more food for a growing world population. AI robots are expected to enhance production, while compensating for lack of manpower, reducing production costs, taking over unattractive (risky, heavy, and dirty) jobs and reducing the burden of food production on the environment. In spite of these promises, however, AI robots for agri-food also give rise to ethical questions and concerns, which have been little researched and discussed until now. To fill this gap, we developed a research agenda for future research in this area. To do this, we opened our analysis to focus on ethics AI robots generally to specifically identify which of these issues are most relevant to agro-robots. The question we want to find an answer to is: what are the most relevant ethical questions raised about AI robots for robots developed for the agri-food sector? And which questions are not mentioned in the literature, which are particularly relevant for agro-robots? Our paper will provide an overview over the key issues and areas which deserve further elaboration to come to a more mature ethics of AI agro-robots.
\end{abstract}

Keywords AI ethics $\cdot$ Robots $\cdot$ Artificial intelligence $\cdot$ Digital farming

\section{Introduction}

Robots have evolved from one-function automatons to intelligent systems which can function in an increasingly independent way, integrated into the everyday settings of citizens (e.g., homes, farms, hospitals). These independent robots are sometimes understood as a variant of Artificial Intelligence (AI). AI is often understood as an addition to these automatons, using computer programs and software, which enables performance that is sometimes described in metaphors that refer to human qualities, such as 'intelligence', 'rationality' and 'autonomy'. In comparison to non-AI robots that have been around for some time, AI robots are anticipated to carry

Mark Ryan

mark.ryan@wur.nl

Simone van der Burg

Simone.vanderburg@wur.nl

Marc-Jeroen Bogaardt

marc-jeroen.bogaardt@wur.nl

1 Wageningen Economic Research, Wageningen University and Research, Droevendaalsesteeg 4, 6708 PB Wageningen, The Netherlands out tasks that require context awareness, learning, problemsolving and logical reasoning, which are also characteristics of human intelligence. AI robots can be understood as AI software and programming embodied in physical machine technology. AI can exist as programming and coding without robotic mechanical embodiment and robots can exist without AI programming. However, for this paper, we will focus on the combination of both in the form of AI robots.

AI robots are being developed for a variety of contexts, such as healthcare, the military, education, production, maintenance of infrastructure, transportation and in the production and processing of food. While there have been robots around in the agri-food sector for some time, they used to function in highly structured environments where there is little interaction with human beings (such as milking robots, or robots assisting in the packaging or storage of foods in horticulture). Nowadays robots are being developed which move around independently and demand a higher level of interaction with living beings (humans, animals, plants) in their environment. These include robots intended for different tasks in farming and horticulture such as harvesting bell peppers (SWEEPER), gardening, or the robotic manure 
scraper (Lely). ${ }^{1}$ Other examples include weeding robots (the 'weed wacker') which make the use of pesticides obsolete, solar-powered drones to autonomously spray weeds with pesticides (ecorobotix), robots that assist farmers in hoeing and harvesting (Naio technologies), strawberry and citrus fruit picking robots, drones to measure the health of crops (agribotix), and AI arms that plant seedlings at the optimum time [30].

The industry for AI robots is rapidly developing and investing a lot of money into these new technologies. For example, John Deere paid \$305 million for the company Blue River Technology, who develop robots that can be attached to tractors to analyze crops and distribute fertilizers and pesticides to plants [20]. John Deere has also been developing self-driving tractors with NASA [56]. While BASF is using drones to measure turf health, and other companies are using them to identify locations, geography, and aerial photos of farms, as well as being used to spray fields within pesticides, herbicides, and water [62]. However, this is not to preclude that agricultural AI development is mostly a Western phenomenon as a recent article demonstrated that China and India are two out of three (US being the third) most influential countries in research in this area [65].

Agribusinesses are investing in different forms of AI robots to do things quicker and more efficiently and therefore there is a lot of hope that these machines will meet the challenges within the agricultural industry, which is to produce more food efficiently for a growing world population, AI robots compensate for lack of manpower, reduce production costs, take over unattractive (risky, heavy, and dirty) jobs and even potentially contributing to realizing the European Green Deal $[4,37]$. The Green Deal has placed a greater emphasis on technological solutions to meet our future environmental challenges and one of the sections in the report gives specific attention to the agricultural sector and how AI can be a beneficial tool for innovation.

However ultimately, the challenge becomes implementing the right kinds of technologies in the right types of situations and doing so in a tactical and optimal way [34]. Overall, AI robots offer great potential and huge benefits for a wide diversity of industries, but likewise, they also give rise to ethical questions and concerns. As there is very little research done on the ethical impacts of agro-robots, we opened our analysis to focus on AI robots generally to identify which of these issues also apply to agro-robots. The question we want to find an answer to is: what ethical questions are raised about $\mathrm{AI}$ robots and what is the relevance of

\footnotetext{
${ }_{1}^{1}$ More info about these robots can be found on the following websites: http://www.sweeper-robot.eu/; http://trimbot2020.webhosting. rug.nl/; https://www.lely.com/solutions/housing-and-caring/disco very-collector/
}

these questions for AI robots in agriculture? Our paper will provide an overview over the key issues and areas that are discussed to some extent and should be elaborated more to come to a more mature ethics of AI robots that are currently being developed.

\section{Method}

While there have been many articles that have conducted literature reviews on the relationship between IoT and agriculture [15, 71], AI in operations environments [34], blockchain in agriculture [57], and even AI in agriculture [65], there has not been very many conducted on the relationship between AI robots and agriculture. As the use of AI robots in agriculture is relatively new and because it is a very under-evaluated area of ethical research, our literature search aimed to understand the main ethical themes surrounding $\mathrm{AI}$ robots and interpret their relevance for $\mathrm{AI}$ robots in the agricultural sector. $^{2}$

\subsection{Search and selection}

Our review is not a systematic review, but it has a looser narrative style, as it was carried out in different stages, over a period of three years. This is due to the fact that the research that lead to this article was done in several subsequential short-term research projects, in which deliverables had slightly different goals and audiences. In the following, we will describe the process leading to our selection and reading of literature.

In the first phase, our search focused on policy reports. As our work was part of a project aiming for a Dutch audience of tech businesses and policy actors, we started by mapping the ethical issues raised about AI robots in policy reports in the period between March and June 2018. To do this, we used LexisNexis as a search engine, which is commonly used to explore ' grey' literature. Keywords such as 'autonomous' AND 'robot' AND 'ethics', yielded 1089 hits. This number was first roughly reduced by selecting only policy reports and excluding articles published in newspapers or magazines, blogs, interviews, reports about workshops and conferences, as well as all reports which were not written in either Dutch or English. After this selection we ended up with 300 reports, of which we scanned the abstracts and titles. After verifying that there were no reports that focused specifically on AI robots for agri-food, we chose to focus on reports that adopted a more generic perspective to ethics and AI robotics and avoided reports that exclusively focused on

\footnotetext{
2 The team consisted of three researchers, 1 female and 2 males. Two of the researchers are ethicists and one is an economist.
} 
military robots, care robots, self-driving cars or sex robots. We ended up with 35 reports, on which we based our analysis, which we described in a project deliverable at the end of 2018 .

In a second stage of research, we chose to expand our reading and include scholarly literature, which started in March-June 2019. The reason for that was that next to our Dutch project, we were also engaged in an EU project on robotics for agri-food, AgROBOfood, and we wanted our results to be accessible to a wider international audience. We used the same keywords as in the first phase and used search engines Web of Science and Scopus, which are commonly used to get a quick overview over scientific publications about a topic. Our search again brought up over 1,000 articles. After eliminating duplicates, non-English texts, technical papers, or other papers with no ethical content and excluding books, book reviews and conference reports, we were left with 134 papers. Based on a thorough reading and analysis of this literature, we delivered a project report and a presentation with an overview over ethical issues related to AI robots at the end of 2019, and in the beginning of 2020.

Based on both deliverables, we decided to work towards a publication in 2020, as there is little work available on the topic of AI robotics for agri-food. As time had passed, however, we needed to update our review, which we did between September and December 2020. This updating was done by identifying relevant papers cited by, or that referenced the original 134 papers using Google Scholar. This method led to a broad exploration of articles. The articles we selected either attracted our interest, because they provided a new insight in ongoing discussions that we already identified in the previous phases, or they added new themes that we had not previously included. It is in this phase, for example, that a few papers about agricultural robots were starting to appear, which allowed to include them in our analysis.

While the work done for this review was carried out at different moments, we did manage to keep a good analytic focus within the team.

\subsection{Analysis}

In the various stages of our research, we conducted our analysis of the texts by evaluating specific ethical issues, establishing five thematic sections, which we describe in the Results section. The five themes were chosen based on two criteria: first, their relevance and frequent occurrence in the literature and, second, their relevance for AI robotics for agri-food. Every time we disagreed about in- or exclusion of themes, we discussed until we reached consensus. An example of our discussion focused on contrasts we initially saw between the omnipresence of a theme, such as moral agency and patiency of robots, in the literature and its relevance for AI robots intended for harvesting, manure scraping or weeding. While these themes first seemed to presuppose a quite speculative perspective to the future of AI robotics, which seemed to have little to do with the developing robots for agri-food, we concluded that discussing them allows to develop an ethical perspective to other themes with high relevance for AI robots for the agri-food sector, such as, for example, a robot's responsibility or liability for accidents, human-robot relationships, and the distribution of labor. This is how we came to the selection of our themes: we chose themes that are either relevant for the agri-food sector, or they offer a stepping-stone towards developing an ethical approach to these themes which are relevant for AI robotics for agri-food.

As the literature about ethics of AI robotics is voluminous and complex, there were also themes that we considered relevant, but which we excluded. During our review we encountered articles that discussed issues related to data that AI robots collect and analyze and which they need for their functioning. Ethical discussions about agricultural data focus on questions related to data ownership, privacy, accessibility and sharing of data, data security and safety of data. Within the field of digital or 'smart' farming these issues are being discussed at length $[21,80,81]$. While we recognize that these discussions are also relevant for AI robotics, we here decided to leave them out of scope as they are not just raised by AI robots, but by any digital system that is retrieving, storing, or using agricultural data.

Considering the choices that we made, this paper does not pretend to provide a comprehensive analysis of all literature on the ethics of AI robots, as that would be an extremely challenging and lengthy process. Instead, we aim to provide a broad, but concise, categorisation of some of the most significant issues that we think can and should give shape to a relatively new sub-area of ethical debate, namely about AI robots for agri-food.

\section{Results}

The themes that we encountered in the literature and that we considered most relevant for the development of ethics for AI robots for agri-food are: (a) autonomy and the moral agency of robots, (b) the moral status of AI robots, also called the moral 'patiency' ${ }^{3}$ (c) responsibility of robots and liability for damage, (d) moral relationships between robots and other sentient beings and (e) the meaning and just distribution of labor. It is these themes that we will discuss in this

\footnotetext{
3 'A moral patient is thus a being who possesses some moral statusi.e., is owed moral duties and obligations, and is capable of suffering moral harms and experiencing moral benefits-but who does not take ownership over the moral content of its own existence' [28].
} 
paper. We will first outline the content of the theme and the discussion about it that we saw in the literature; after that, we will discuss the relevance for the further development of ethics of AI robots for agri-food.

\section{1 a. Autonomy and morality of robots}

As AI robots are increasingly autonomous, and autonomy is regarded as the capacity that makes human beings moral agents, it is perhaps unsurprising that a lot of ethical discussion focuses on the question whether robots can be considered moral agents too-and who should take responsibility for their actions as moral agents. There are different approaches to that. Some ethicists focus on the robot-makers, the engineers, and designers, and argue that they should take responsibility for the robot's actions. Robertson et al., for example, ascribe ethical responsibility for the design of the machine to the engineer [64]: 2. Yet they also advise engineers to consider the values of end-users and other stakeholders: they call this approach ethical co-design [64]: 4. The co-design approach stems from the participatory design movement, which started in the 1970s [22]. It takes as a presupposition that end-users possess a kind of expertise (experiential expertise) based on which they need to give input to design [85]. In this way, end-users can contribute to the values in the design process and therewith can make the end-product (the robot) acceptable to users. Users, with their experiences and values, help engineers make more responsible decisions about the design of the robots, as they can help make sure that robots 'act' in a way that is desirable or acceptable to them.

A significant portion of the literature moves, however, beyond the idea that engineers are the primary addressees of moral reflection about robots. As robots become more and more autonomous, they could also become capable of making free choices. Robot agency and human agency could then become hard to distinguish, thus raising the question whether robots should be considered moral agents too. This question is discussed in abundance in the literature [2, 3, 5, 27, 39]. Authors who look at robots as agents capable of free choice do not ignore the role of the engineers as designers of those robots (in fact, they argue that the engineers should program the robots in such a way that they can act as moral agents) but they anticipate that once robots have been created, they will act with a strong degree of independence. Some argue, therefore, that these robots should also act morally, as 'intelligence must come in conjunction with ethics' (Crnkovic et al. [27]: 61/62) 'Ethics by design' is a job that involves building ethical behavior into the design of a machine: '(..) development of cognitive machines with "built-in" Machine Ethics is the prospect of a deeper understanding of the mechanisms of ethical behaviour in humans.'
(Crnkovic et al. [27]: 62) Robots, according to them are artificial moral agents (AMA).

Authors who take this approach often engage in a theoretical discussion about what constitutes moral agency and how it can be known that robots possess it. Some propose (the design of) an empirical experiment, like the famous Turing test, ${ }^{4}$ but adding morality. This idea was launched by Allen and Wallach [3], Wallach et al. [86]. In the Moral Turing Test (MTT), interrogators are asked to distinguish human moral reasoning from computer moral reasoning. If the human interrogator cannot distinguish the machine, it can be considered successful as a moral agent. The comparative Moral Turing Test (cMTT) instead asks the interrogator to compare the answers of a human actor and a computer and assess whether one of them is giving a less moral answer than the other. If the machine is not identified as the less moral of the pair, it has passed the test. [2]: 255).

Generally, these cMTT experiments take the human moral agency to be the norm that robots need to satisfy, whereas human moral behavior is known to be fallible. Allen et al. argue in response to this criticism that the artificial moral agent which is more rational and consistent than human beings should be morally infallible and should satisfy higher standards than humans. Another criticism is that during a MTT or cMTT, it is unclear whether the machine understands what it is speaking about, or whether it is simply reciting verbal phrases. Moreover, it remains quite unclear whether a robot that utters the right phrases also engages in moral reasoning and would eventually do the right actions ([7]: 105). Instead of focusing on verbal utterances, Arnold et al. propose to opt for verification, as this 'looks at the whole system', design as well as eventual performance, to determine what outputs the system will produce and why. ([7]: 109).

Those authors who trust that robotic systems will have moral agency, usually also engage in a theoretical discussion concerning what ethical theories should guide robotic behavior, such as deontological or utilitarian ethical principles, [76, 77], virtue ethics, which implies a period of moral learning for the robot $\left[2^{5}, 25\right]$, or behavioral universals of mammals [69]. Some consider the more abstract principlebased ethics attractive, as they can be programmed into the system. Other authors, however, argue that this might lead to too rigid robotic behavior, which is unable to respond with flexibility to specific contexts $[5,27,49]$. To become more

\footnotetext{
${ }^{4}$ The original Turing Test asked human interrogators to ask questions to human test subjects and a computer and they had to distinguish human reasoning from computer reasoning based on the answers.

5 Allen et al. suggest looking at the development of AMA's as a 'simulated childhood', during which the computer receives feedback on the acceptability of actions and learns from it. (Allen et al. [2]: 258).
} 
responsive to context, Anderson et al. [5], suggest guiding the behavior of robots by a framework of principles that are established bottom-up through consensus of ethical experts about concrete cases (Anderson et al. [5]: 2). McGrath and Gupta [49] propose to use stories (including science fiction stories) to teach robots to respond well to the specificities of context and Scheutz et al. [63] defend the development of 'moral competencies' in robots, which enables them to respond in appropriate ways to contexts.

In general, however, the lesson learned from the literature focusing on the moral agency of robots is that the moral demands that can be rightfully placed on robotic systems, depends on their degree of autonomy. Crnkovic et al. [27] argue that the ethical competence of a robot should depend on its actual intelligence and field of application: not all capacities that human beings possess are attainable for robots and it is not always needed to give robots these capacities. ${ }^{6}$ Whether moral principles should be programmed in the robotic system depends on the contexts in which it is used. Robots are usually designed to function in a more restrained domain with less need for complex moral decision-making. This is certainly the case for AI robots intended for the agri-food sector. Agricultural AI robots are for example designed to plant seeds, harvest grain, test nutrient levels in soil and water plants. The actual intelligence required for these tasks, while still very important, does not require the same kind of ethical competencies of robots in other sectors where robots will be directly interacting with, providing decisions for- and affecting human beings. The ethical actions and conduct of agricultural AI robots and their ethical consequences are, therefore, very different and probably less demanding for the decision-making power of the robot.

This explains perhaps also why there has not been a lot of discussion in ethics of AI robots literature about implementing a specific ethical ideology or framework into agricultural AI robots, such as utilitarianism, virtue ethics, or Kantianism. This is probably because of the limited autonomy that robots had until now in agri-food, which explains why there was not yet a need to consider the morality of their decisionmaking. When robots in the agricultural sector are becoming increasingly autonomous, it may however be fruitful to think about this. It is expected that this will happen, because the relative autonomy of the robot may make it more productive, while restraining this autonomy may stifle innovation

\footnotetext{
6 'Adding the requirement for ethical behaviour to a robot or a softbot does not mean that the artifact should possess the totality of human moral capacities, just as an intelligent artifactual system does not possess all of the human intelligent capabilities. The requirement of artifactual ethical competence for a robot/softbot should be in accordance with the artifactual agent's intelligence and depend on the application.' (p.64, Crnkovic et al. [27].
}

and new ways of progressing these technologies and thus the industry [10], p. 130). The scarce debate that has taken place on $\mathrm{AI}$ in agriculture, has focused on the impact that $\mathrm{AI}$ robots may have on the autonomy of farmers working in the industry whose decisions may be steered by AI or altogether taken away from them [66]. Farmers are concerned that AI robots will reduce the control they have over their farm [66]. There is also fear that decision-making will be transferred to tech companies and agribusinesses outside of the farm that design and produce the robots (Ryan [67], thus leading to questions about the (possibly manipulative) power and control that they exercise over individual farm businesses and the autonomy of their managers, the farmers. One of the possible ways to answer to these fears may be to program ethical principles into the robots, which would prevent these types of impacts.

\section{2 b. Moral status (patiency) of Al robots.}

Anticipating a future in which robots increasingly think and act like human beings, authors have raised the question whether robots can and should have rights similar to human rights. Some argue that robots cannot, and should not, have rights. These authors consider the prospect of ascribing rights and duties to robots ridiculous: we are not going to send robots to prison or give them fines or accuse them of abuse. These authors think that we cannot give rights to a machine, and it is morally repugnant to try: 'No matter how independently, automatic, and interactive computer systems of the future behave, they will be the products (direct or indirect) of human behavior, human social institutions, and human decision' [46], p. 197).

Others, such as Ben Goertzel [40], state that robots will develop higher forms of intelligence in the future, which will justify them having rights. They argue that it is not a question of if this will happen it is a question of when. According to Asaro, we should even grant them rights before they demand them [8]. Joanna Bryson [17] agrees that we may be able to create machines that need rights, but we should avoid this by not designing them with qualities that make them deserve rights. Robots should be built with enough capabilities to serve our needs but never be designed to merit the ascription of rights [17]. In contrast, Kate Darling [31] states that even if this were the case, we should still ascribe rights to robots because it feels wrong to harm them, as we often perceive them as being like us, with the abilities to feel pain, distress, and awareness. We should grant robots rights because violating rights of robots, violates our humanity and may condition us to act in similarly inhumane ways towards other humans. While John Danaher [29] claims that if robots are behaviorally equivalent to us, then it would grant them similar moral patiency. If we are unsure of their internal workings and makeup, but they 
appear behaviorally equivalent to us, then we should grant them moral consideration.

David Gunkel [41, 42, 43] and Mark Coeckelbergh [24], following a Levinasian approach [48], propose that we should think differently about the problem of robot rights. The debate often focuses on the structure of ontology before ethics, that is, on the capacities of the robot which may be deserving of rights, but Levinas [48] places ethics before ontology, according to Gunkel. It is enough to be confronted with others in the world that we must interact with before we can know anything about their capacities or inherent mental life. Moral consideration is not based on ontological criteria, but on the encounter with the Other (written with a capital to accentuate that it may differ radically from us and deserves our awe) in the social world. Gunkel uses this insight for robot ethics and concludes that this encounter would become unpractical and morally void as it would make us 'obligated to consider all kinds of others as Other, including other human persons, animals, the natural environment, artifacts, technologies, and robots. An "altruism" that tries to limit in advance who can or should be Other would not be, strictly speaking, altruistic' [41], p. 97).

Considering the question whether AI robots should have rights, is also sometimes considered problematic as it distracts us from actual problems relating to human rights which deserve our attention. Birhane and van Dijk [13], for example, claim that the robot rights debate is misguided, self-serving, and re-enforces oppression of minorities and the poor. They argue that robot rights are so far into the future that it overlooks current human rights infringements. The entire race towards an AI superintelligence will come at the costs of the resources, labor, and exploitation of developing nations. Also, the robot rights debate often equates the rights of robots to how people of color, women, and minority group rights were (and still are) being stripped from them, which is considered dehumanizing for these people.

This comparison between human beings and robots with respect to rights is perhaps not the most urgent theme to discuss in relation to the developing AI robots for agrifood. The agricultural sector has adopted the use of flying drones, large AI tractors, and huge mechanical arms, but there have not been AI humanoid robots yet. There would be no requirement to infer a moral consideration of these types of agri-robots because it is quite clear that their abilities, limitations, and their robotic structure do not resemble human beings. The agricultural sector has no clear indication that it aims to build robots with many of the traits that may necessitate the ascription of rights to them. Metaphors such as 'autonomy' and 'thinking' or 'intelligence' invite this comparison between humans and robots, but for robots in the agriculture sector, we do not immediately see how the moral status of developing robots would become a pressing issue. Yet, we do recognize that the discussion about the moral patiency of robots is hard to ignore, if AI robots are ascribed a level of autonomy and moral agency, or if robots interact in a human-like fashion in social relationships with humans. If not for anything else, we included this theme in this review because it raises relevant questions about the ways in which we want to develop agri-food robots toward the future. Do we want or need to shape robots as humanoids in agricultural industries-or not? While we imagine it makes sense to give robots a humanoid form in care settings, it may be questioned whether this is needed as much in the agri-food sector, for AI robots play a different role here. Questions about whether or not robots deserve moral patiency will more likely arise when robots look like humans and when their interaction with humans resembles social interaction between human beings. Robotic systems which do not have a human shape or form and which do not interact with humans in a polite, empathic and social manner on the workfloor, most likely will stop raising questions about the moral status that is ascribed to them. The question is therefore whether and to what extent AI robots for agri-food need to be humanoid and function like humans in society.

\section{3 c. Responsibility and liability for harms caused by robots}

There are many harms that AI robots can cause to human beings. AI robotic surgeons may cause someone's death during surgery, self-driving vehicles may cause avoidable accidents or social robots could cause emotional harm to patients in care settings by being insensitive to their needs or uttering someone's secrets to outsiders. Domestic robots could even be used for burglary: '(..) A robot in your own home could either be reprogrammed by people with criminal intent or they might have their robots carry out the theft' [78]. Concerns are also raised about robots that are hacked and used for malicious and nefarious purposes: 'in the wrong hands, they could be used to commit crimes including acts of terrorism, such as delivering lethal substances or weapons into crowded areas' [10]: 132). The degree of autonomy that a robot possesses also relates to the discussion about whether responsibility can be ascribed to robots for eventual adverse effects, or to the ones who employ the robots to do certain things (such as hackers).

As autonomous robots may move beyond the limitations of what we understand to be 'instruments', the question is raised whether responsibility can be ascribed to them for the harms that they cause. Robots that make independent decisions are often considered problematic in health care [83], Coeckelbergh [23]. In cases where a robotic surgeon works independently, it is questionable who is responsible (and liable) if something goes wrong [59, 70, 83], Mavrofourou et al. [53]. At present, surgeons are the ones who are responsible (and liable) for their patients, but when robots 
work independently, surgeons may no longer be able to take charge $[53,83]$. This has led some authors to question whether we are putting too much trust or reliance on robots [67].

The level of responsibility people give to robots partly depends on what robots are capable of, but it also depends on the ascription of accountability and liability for harms in the context of use. For tasks with a high risk, it is harder to use a robot because legislation is often unprepared to deal with liability for adverse effects caused by autonomous robots [53]. The European Parliament Committee (2016) ${ }^{7}$ reports that existing legislation is unclear on who is responsible for damage and compensation when it is a robot that causes the harm.

Different solutions are proposed for this liability problem. The COMEST Working Group [26] argues that for robots with a high degree of autonomy and self-learning abilities, it is difficult to track what caused a robot's past actions, thus making it hard to track the origin of adverse events in the way 'black boxes' can in planes (COMEST Working Group [26]: 37). Other authors question whether the cause of harms should be traced back to just one actor, or a group of actors, such as the manufacturer, programmer, owner, and user. It may be more appropriate to speak about the distribution of responsibility for the harms among actors. It is for this reason that the European Parliament Committee (2016) proposes to create a compensation fund to which all partiesmanufacturer, programmer, owner, and user - contribute in varying proportions, and which allows compensating for eventual damage inflicted by a robot to property. This would allow making a combination of parties liable for damage caused by the robot, instead of charging only one with all the responsibility.

This fits with a solution provided by [10] who allocate responsibility depending on the type of error that caused the harm. For example, if the error can be traced back to the design of the robot, then the manufacturer should be held accountable; if it is open software, then the developers of that software are to blame; if caused by the robot that is in process of learning, then the user/owner is responsible who is supposed to teach the robot; and if the robot is hired out, then the hirer is responsible. There needs to be 'a causal link between the harmful behavior of the robot and the damage suffered by the injured party' [10].

In the context of AI robots for agri-food, all these issues around responsibility and liability for accidents, and hacking, are relevant topics for ethical debate. Robots intended to work in horticulture greenhouses, stables and fields can also cause damage to human beings, plants, animals, and

\footnotetext{
7 https://www.europarl.europa.eu/doceo/document/JURI-PR582443_EN.pdf
}

buildings, which could very well lead to economic loss, time wasted, injuries, or even death of people if robots are out of control or malfunction. When the autonomy of robots for agri-food increases, they may increasingly act outside of the design and intent of their developers and/or users when they cause harm. There is an agency that is disjointed from the intent of the designers of the technology which causes the harm, so it is said to be difficult to blame the human designers for the actions of the robot. But it also seems strange to not make the makers of the technologies accountable at all [67]. For example, if a self-driving tractor's computervision mistakes a rock for a dog, swerves and kills a farmer, should companies like John Deere be held less accountable than if their non-automated tractor's brake malfunctions, crushing a farmer to death? The level of autonomy seems like a significant thing to discuss, but the question is also whether the manufacturer should be any less accountable if there is a clear indication that the incident was caused by the programming/development of the technology. This is certainly an issue within the agricultural sector, and its deployment of AI robots, that needs to be clarified. As we have seen with self-driving vehicles, generally, society is stricter towards death caused by these large autonomous robots more so than accidents caused by human drivers (see the controversies over the Tesla $\mathrm{S}$ deaths in recent years), which may also materialise during the use of AI robots in agriculture, as well.

Another topic for debate concerns the right timing of discussion about these issues for AI in agri-food. Some claim that the issues surrounding autonomous robots on the farm will not materialise for some time or will cause only minor issues. For example, in an article citing a manager for a large European agribusiness stated that even if their robot malfunctions, the 'damage that such a robot can do in one day is nearly negligible' [66]: 18). However, even if responsibility ascription for harms is not considered to be a problem right now, it may become a problem when robots in the agri-food sector become more and more independent and incidents come about that injure people, impact farmers' productivity, waste their time or cause unnecessary stress. Furthermore, agricultural AI robots can leak toxic material, pollute, and altogether harm the natural world, not just on the farm. Examples such as these require also careful consideration, responsibility allocation and development of appropriate ways to prevent it [54]. Responsibility and liability for harms are, therefore, an important topic for consideration in agriculture.

\section{4 d. Relationships between robots and other sentient beings}

As AI robots are often intended to interact with humans in a variety of contexts, relationships of robots with human 
beings or animals are an important theme in the literature [11, 14, 58], Sparrow et al. [74]. Some of the literature focuses on the acceptance of autonomous robots that are used for various purposes (military, care, transportation etc.), using large scale surveys [75]. A survey among 250 robot ethics experts and lay responders shows that the accepted level of robot autonomy does not depend on efficiency/effectiveness of the robot, but on public perception to the field of application (for example, in care, the military or in traffic) [55].

Other publications claim that robots with human characteristics-like a mouth and eyes-help to enhance human acceptance of -and trust in- the robot in some contexts. However, sometimes this trust is lost afterwards, as people may expect to interact with a human being when the machine looks like it, but immediately notice that it is not human, feel alienated and refuse to interact with it any longer. This is referred to as the 'uncanny valley' [50,51]. If robots appear too much like us, people are feeling unnerved, apprehensive, and uncomfortable,this also plays a role when people are unable to distinguish between robots and humans in their everyday lives.

The quality of human-robot relationships is also discussed, concerning social robots and care robots. Companion robots are designed to engage in relationships with human beings. Some function as a friend or buddy for children or elderly people [45, 60]. Given these 'friendships' between human beings and robots, some publications inquire into the esthetics of the robot and the type of social and emotional contact that it is appropriate to generate between human beings and robots.

As emotions are considered an important constituent of relationships, as well as moral behavior, some scholarly studies focus on the communication of emotions between robots and human beings (Briggs et al. [16, 58]. Ojha et al. [58] state that to function in social life, a robot's display of emotions should not only be believable but also acceptable: if a robot shows anger when a young child pushes it around or kicks it, this may frighten the child. Ojha et al. argue that the robot should be able to reason ethically about whether an emotion is fitting in a situation, and this should be part of its computational model of emotion. In line with this idea, Briggs et al. [16] carried out an experiment aiming to study whether robots' display of emotions, can promote ethical behavior in human beings. However, '(..) these displays will only succeed if the human operator is socially engaged with the robot. For successful social engagement to occur, the human interactant must find the robot believable' (Briggs et al. [16]: 345). A significant number of test subjects that took part in their study changed their behavior in response to the (emotional) protests of the robot. Believability played a large role in their motivation to do so. Those who adapted their behavior were more likely to ascribe affect/agency to the robots, than those who did not change their behavior.

The instrumentalization of people, as well as a loss of skills in humans, are also topics of consideration. In healthcare situations, for example, the concern is that the use of robots as substitutes of human care-givers will lead to dehumanization, objectification or instrumentalization of the recipient of care. Deployment of robots for certain tasks in the healthcare sector, may lead to diminished (or disappearing) human contact between the caregiver (professional or family member) and care recipient. This raises concerns about the dignity of the care recipient who will have fewer interactions with humans and as well as deteriorating social skills of care-givers [83].

Deteriorating human skills, furthermore, play a role in considerations about some types of AI robots, such as self-driving cars: when people come to rely on driverless cars for their daily commute, their driving skills will deteriorate, which may produce new dangers as driverless cars may need humans to interfere at some moments [74]. People may become more careless or come to depend on these cars completely: busy parents may send their children to school in a driverless car or people with physical or cognitive constraints can use driverless cars and therewith enjoy more independence, but they may not be able to interfere in the driving when needed. In ways such as these habits may change, which produces new dangers.

While the body of literature discussing the effects of AI robots who interact with humans on the lives of those humans is quite large, there has been a much smaller focus on their effects on the non-human world. The article by Bendel [11] discussing the (dis)similarity of ethical relationships between human beings, autonomous robots and animals is one of the rare exceptions. Bendel states that autonomous robots and human beings can act as moral agents as they have the freedom to choose and act independently, but animals cannot for they lack autonomy. However, they are still entities of moral concern, whereas machines are not. Therefore, Bendel argues, robots and human beings should take morality into account concerning animals: they are moral agents and animals are worthy of their moral consideration due to their status as sentient beings who can suffer.

For AI robots for agri-food, relationships with humans and animals are also an important topic of consideration. There has been little research done until now on many of the topics that were raised in the broader AI robot's literature on human-robot relationships. For example, there are no agricultural robots imagined functioning as companions, or friends or with built-in emotional capacities of any sort. However, there are robots being designed to work side-byside with human 'colleagues' to pick fruits or harvest vegetables, or to interact with animals in the barn where they clean up the manure, or functioning as an assistant of the farmer 
in the field [61]. While there are no personal attachments between humans and agricultural robots, robots are certainly imagined functioning in intimate working collaborations with human beings and animals. In any place where robots and humans interact closely, or where humans interact with animals, questions may arise as to the preferred way for them to interact and the desired relationship to form. Questions may be raised about what constitutes a 'good' collaboration, which should inform the ways in which the robot should be designed to function. Very likely, the moral character of this relationship will be different from the one realized in a caring context or a military context.

One of the questions to raise would be whether robots in agri-food should invite humans to form attachments with them. It is of course a possibility that attachments will be formed anyway, like many other robots without social functions have had humans bonding with them, such as US soldiers in Iraq and Afghanistan becoming attached, and even risking their lives, for their Packbots [79]. But the type of relationships that should come about between robots and human beings could also be a topic of ethical discussion. In a farming context, robots could be designed in a way similar to tractors and vacuum cleaners which do not invite any human-like attachment. But there could also be reason to shape AI robots in a way that invites farmers and growers to relate to it. There is the potential that AI robots would replace many human roles on the farm, reducing much of the heavy work, but also the number of human contacts that a farmer will have, and often cherishes, on his farm. While the debatable value of the impact may not be as evident as the restriction of human contact in the care and health sectors, it should still be considered when developing and deploying AI robots in the agricultural domain. The technology is not yet advanced enough to replace some roles, such as agronomists, but even if it were, (for now) many farmers would still prefer to consult with a human agronomist [66]. Farmers value interacting with other people, especially because they often work alone and have little possibility to exchange thoughts with others. This could be a reason to design a robot more like a human being.

\section{5 e. Meaning and (just) division of work}

There is much discussion in ethics of AI robotics around the acceptability of a robotic workforce and the value and meaning of people's work [47, 82, 83]. Using robots for dirty, dull, heavy, dangerous, or precision work is acceptable to many, as this saves human beings from having to fulfill these tasks. It is also anticipated, however, that robots will soon master many skills human beings possess and will be able to fulfill tasks cheaper and more efficiently than humans can. This means that much routine work will no longer be carried out by human beings (AWTI [1]: 5).
In some fields, such as health care, using a robot as a substitute for a human worker raises particularly sensitive questions (Bertolaso et al. [12]. While it is considered unproblematic for robots to take over routine caring tasks, which require no emotional, intimate, personal involvement, it is considered more appropriate to reserve more personal and caring jobs for humans (Kool et al. [47]: 56). It is also acceptable that robots and human beings collaborate, such as when a person is present to instruct the robot or when the doctor is assisted by a robot (Est and Kool [82]: 165), or when a robot inspires positive behavior in humans, such as when it motivates a patient to comply with his or her treatment plan. However, to preserve the dignity of the persons who are cared for, full automation of caring tasks is considered problematic. Care should involve meaningful human contact, which cannot be substituted by a robot (Kool et al. [47]: 77; Bertolaso et al. [12].

The course that discussions take about the type or tasks that should be allocated to robots and the jobs that will continue to need people, partly depend on the capacities ascribed to robots. Brynjolfsson et al. consider the arrival of intelligent machines which can do human jobs more efficiently and cheaper part of the reason for current high unemployment rates (Brynjolfsson et al. [19]. Autonomous robots will take over human jobs when their abilities surpass ours and they wish to put this on the agenda of policy makers.

Others anticipate the development of a whole new industry and market around robots, which will change the range of jobs that is available at present and may even enhance economic growth and welfare (Frey et al. [38], Van Est et al. [82, 83] European Parliament Committee 2016, AWTI [1]. This may have very favorable effects on people's welfare, with an acceptable distribution of wealth. On the other hand, there is a fear that robotization will lead to the loss of jobs, as human tasks are taken over by robots (Kool et al. [47]: 57; Brynjolfsson et al. [19]. Robots may push people to develop new skills, specialize in different tasks that robots are unable to do, or maintenance of the robots.

However, some argue that widespread use of robots, as well as increased automation, could diminish the amount of available lower and middle-class jobs. That will increase inequality in society (AWTI [1]: 18), through a divide between highly educated citizens who can use the opportunities on the job market that robotics and digitization offer and those who cannot (European Parliament Committee 2016: 22; Est and Kool [82]: 160-161). This 'job polarization' (Est and Kool [82]: 166) raises questions about distributive justice (of jobs, of wealth) and participation in society.

All the questions raised about the job market are very relevant for the agri-food sector, but they have been rarely discussed at length in the scholarly or policy literature $[9,36$, $61,66,72]$. While the rollout of agricultural AI robots is still 
Table 1 Research questions derived from our AI robot literature relevant for agriculture

\begin{tabular}{ll}
\hline Themes & Possible questions to raise \\
\hline Agency & In what contexts in agri-food would the development and use of AMA be valuable/required/acceptable? \\
Patiency & $\begin{array}{l}\text { What ethical standards should guide the behavior and choices of such a robot and should be built into it? } \\
\text { Does it make sense to speak of (some) agri-food robots as having a moral status? What features do they need to have to be } \\
\text { worthy of moral consideration? And what would the ascription of rights to them entail for their position in the social world, } \\
\text { for example with respect to their role in the workforce? }\end{array}$ \\
Responsibility & $\begin{array}{c}\text { Can agri-food robots be considered as 'responsible' agents? What (individual; social) approach to responsibility is most appro- } \\
\text { priate when considering AI robots in agriculture? Can robots be considered responsible, or are (only) the robot-developers or } \\
\text { users' appropriate responsible agents? What should responsibility distribution/sharing look like when using agricultural AI } \\
\text { robots? And (how) does the concept of liability (for damage/accidents) apply to robots and/or to (collaborations) of people? } \\
\text { What is the value of robot-human relationships in agri-food? What kind of robot-human relationships would we like to come } \\
\text { about in various agri-food contexts? What impacts do robots have on the well-being of other sentient beings (animals, } \\
\text { humans)? What impacts should it have? } \\
\text { What is the value of the effects of AI robots on various labor contexts in the agri-food sector? What is the value of its effects on } \\
\text { the job market? How ought these effects to be evaluated with respect to justice and fairness ideals? }\end{array}$ \\
&
\end{tabular}

relatively new, there is the possibility that some of the jobs previously done by humans will be replaced by robots. This may require farmers/growers and their employees to learn new skills that cannot be done by robots or update their skillset to adapt to these new technologies (e.g., learning selfdriving tractor functioning, instead of traditional tractors). It may lead to a new opportunity to learn skills for using AI technologies for the future [72]. Robots are expected to fulfill a role, because human laborers are considered costly and reducing costs leads to higher profits (Pekkeriet et al. [61]. But also, because in some areas (e.g., North West Europe) capable laborers are increasingly difficult to find. There has been a consistent decline in individuals working in agrifood over the past decades. For example, in the US, in 1900, $41 \%$ of employees worked in agriculture, while in 2000 , this dropped to only $2 \%$ [9]. It has declined over the past several decades and often there are huge shortages of available farmers and agricultural workers. As the availability of human beings to do agricultural jobs is expected to decline further in the future, agricultural AI robots are considered attractive as they can fill the gap humans leave behind [72]: 51). Also, in many countries, the demographic of farmers is quite old, despite it being a profession which demands fitness and quite intense physical labor. For example, the average age of farmers in the UK is 58, and in addition to the decreasing levels of youth taking up the profession, this may further exacerbate the strain on the labor market of the industry [36]: 6).

There is, however, a much greater agricultural labor elasticity in developing countries than developed nations, where the demographics is also quite different, as there are currently low levels of technology use, but high levels of human labor in the sector [52], p. 118). Autonomous robots could be regarded here as offering great potential through the reduction of labor-intensive work in developing countries, while increasing productivity, but they could also be considered as taking away badly needed jobs for locals or they may further disenfranchise humans within this sector. A careful balance needs to be struck about where, when, and how to implement AI robots within different agricultural practices. Introduction of autonomous robots as replacement of human beings in the labor force therefore raises also ethical questions regarding the impact this may have on human opportunity to earn a living, in low-skilled and low-paid jobs, and questions regarding just distribution of benefits. These may include the benefits that robotics provides, which may not be accessible to all farmers, but also the benefits of having a job that allows to earn a living which may no longer be available for some.

\section{Discussion}

Based on the literature, we identified some key ethical discussions related to autonomous robots and explored their relevance for the agri-food sector. All in all, we can conclude, that autonomous robots for the agri-food sector have received very little attention in the ethical literature. But the literature studied, as well as the few articles focusing on the agri-food sector that we identified, does allow us to develop a research agenda that can form a starting point for further ethical research in this area. Our first exploration of the questions that could be put on the research agenda for AI robots intended for agri-food are noted in Table 1, but this is by no means exhaustive, and more questions may be added.

In addition to these follow-up questions, which require further exploration, a prevalent issue that we identified in our research was the re-emerging idea that robots have intelligence like human beings or have the potential to have a similar type of autonomy as us (a-b). Both themes often shape much of the basis upon which other discussions 
Table 2 Future research questions derived from our research

\begin{tabular}{|c|c|}
\hline Themes & Possible Questions to Raise \\
\hline $\begin{array}{l}\text { Accessibility and } \\
\text { Benefit Distribution }\end{array}$ & $\begin{array}{l}\text { What are benefits of AI robots? Where do AI robots offer benefits and to whom? What kind of farms will it benefit, and } \\
\text { which will not? What is the just distribution of the benefits? }\end{array}$ \\
\hline Good farming & $\begin{array}{l}\text { What does 'good farming' mean? (How) can AI robots contribute to it? What are effects of the use of robots on the farm } \\
\text { and how is/should this be evaluated? (for example, with respect to the level and quality of production, (flexibility of) } \\
\text { choice of crops, physical burden of work, leisure, social relationships of the farmer on and around the farm) }\end{array}$ \\
\hline Animal Welfare & $\begin{array}{l}\text { What is the meaning of animal welfare? (How) can AI robots contribute to animal welfare (livestock and wild animals)? } \\
\text { How should we weigh the interests of animals in relation to the interests of human beings? }\end{array}$ \\
\hline Environmental Issues & $\begin{array}{l}\text { What is sustainable farming? (How) can AI robots contribute to realizing it? How should environmental concerns be } \\
\text { evaluated in relation to other (economic) concerns of the farmer? Do AI robots also produce environmental harms? } \\
\text { What kind of environmental harms, resulting from these robots, is deemed acceptable, and why? }\end{array}$ \\
\hline
\end{tabular}

within AI robot ethics, such as responsibility (c), AI robots' relationships with human beings (d) or replacing them in the labor force (e). All the ethical issues discussed around these topics seem to presuppose human beings used to be unique in the world, but now some robots may have similar, or even superior, capacities than us. While we understand these questions to be important when it comes to the interactive relationships between human beings and robots, we also think that this focus eclipses other important issues. When we, in ethics, continue to occupy ourselves with all these questions related to how robots resemble us, this focus on the resemblance with humans has the potential to blinker us to the other issues that could come up and which would have more direct concrete relevance in the agricultural sector.

While we do not want to discredit much of the philosophical analysis taking place around the future of robot agency and patiency, it is in our view not the theme that deserves priority in ethical discussions of AI robots intended for the agricultural industry. Most of the tasks required on the farm do not necessitate competencies that require moral decisionmaking and 'human-like' autonomy. So far, the agricultural industry has therefore veered away from developing robots that look and act like human beings. While we are open to explore whether farmers would like their robots to have a humanoid form that they can relate to and grow attached to, establishing a good robot-farmer relationship does not seem to deserve the same priority as it has in the development of robots for care contexts or education contexts. For the increasingly independently functioning robots that are developed for agri-food contexts it seems much more important to inquire into the effects on the rights of people that are anticipated to collaborate with these robots, rather than postulating on some future scenario in which robots are outsourced and defend their labor rights which seems to be highly speculative. We therewith acknowledge Birhane and van Dijk's [13] call to put greater emphasis on present human rights issues related to robot use, rather than focusing on a futuristic scenario of robot rights. Some of the additional questions and issues that we identified, which are of a more immediate concern for agricultural AI can be seen in Table 2.

Accessibility and benefit distribution of agricultural AI robots, as well as what 'good farming' means, has started to receive more attention in the literature, with Sparrow and Howard [73] article highlighting some of the concerns addressed in Table 2. In this article, they describe a situation whereby farmers in wealthier nations, and regions, are able to outcompete their poorer neighbors, thus, leading to equity challenges for the industry (p. 823). Western, wealthy, monocultural farmers will be the most likely benefactor of AI robots, as they are the ones who can afford the large investment costs and farm types to innovate through these new technologies.

In this paper, the authors also pointed to a disempowerment of employees on the farm, particularly, migrant, and seasonal workers. They state that there is a concern that AI robots will not only replace them, but that powerful technological companies and agribusinesses will purposely make it difficult to obtain visas, encourage stricter immigration policies, and altogether, make the implementation of AI robots a more appealing option than hiring these laborers (Sparrow and Howard [73].

AI robots also have an impact on accessibility and inclusion within the sector. As Sparrow and Howard [73] noted, there is the potential that the largely male-dominated profession of computer science and AI will further exacerbate the (already low) uptake of jobs by women in the agricultural sector.

The ethical debate on autonomous robots is, in our view, quite anthropocentric in its approach. It is often starkly overlooking the effect of robots on non-human organisms, ecosystems, and the natural world. This anthropocentrism has tendency to overlook important impacts of farming on the environment, which may be diminished or prevented by the use of robots, such as the use of polluting pesticides which become obsolete when weeding robots take away the weeds, or the manure scrapers that reduce the nitrogen emissions on farms. On the other hand, robots can also cause harms to 
the environment, for example when autonomous tractors are involved in spraying the pesticides, or when the robots need a lot of energy to function.

Issues raised by AI robot development in the agri-food sector often relate to animals, plants, or nature more generally. These non-human aspects of life deserve more attention in ethical discussions about robots, especially about AI robots for agri-food, but also for other fields such as maintenance of infrastructure (such as gas- or oil pipes) or production robots. For example, in a recent paper, Daum [33] asks whether AI robots will bring an ecological utopia or dystopia in the future. He provides a utopian scene where animals are enjoying their habitat, the ecological system functions effectively, all spawned on by the wonderful job that AI robots are providing to ensure this desirable future. Contrary to this, he also portrays a dystopian scenario, whereby, agricultural robots are polluting the environment, we genetically modify 'square' tomatoes to accommodate robot arms, and the dissolution of the family farm. In addition, Sparrow and Howard [73] also highlighted the possibilities that AI robots will allow farmers to use more pesticides as they are not directly affected by them, the heavy robots may cause soil compaction, and also, genetic modification.

The ethical debate about robots could also benefit from more focus on the well-being of animals. In the agri-food sector, the use of AI robots typically leads to less physical contact between farmer and animals, which could raise questions about animal welfare. In connection to an older type of robot, the milking robot, which is not (yet) autonomously moving through the stable or field, but which is located at a fixed location, it was already mentioned that it leads to cows who "have lost familiarity and mutuality with human beings by oral communication, emotional exchange, affection through hugs" (COMEST [24]: 35).

Similarly, it is expected that animal welfare can be impacted because of implementing AI robots on the farm, as the farmer can become more focused on data about his cows, rather than getting information from seeing and feeling how the cow is acting, which would have been part of the process during manual milking (Bos et al. 2016). This alters the meaning of 'animal welfare' for farmers and changes their deliberation about animals' needs (Bos et al. 2016; Driessen and Heutinck [33]). However, some have said the opposite of this, that the use of agricultural robots has actually allowed farmers more time to spend with their animals and build better relationships (see Lowenberg-DeBoer TED talk: https://www.youtube.com/watch?v=lhQosWrq0vo). ${ }^{8}$ Furthermore, the use of robots is eventually also expected to lead to a change in farmer's skills that become more technology-dependent, as well as to the animal's behavior:

\footnotetext{
$\overline{8}$ Thank you to one of the anonymous reviewers for providing this resource.
}

"there are examples of cows that refuse to follow the system (milking robot) being culled because of their independence" (COMEST [26]: 35). Robots are not only affecting the relationship between the farmer and his animals, but also directly impact on the animal's welfare. This is a concern because '[r]obots, sensors and unmanned aerial vehicles (UAVs) also have the potential to emit toxic material, fumes and waste into their surrounding environment' [66], p. 12).

Furthermore, there is also the possibility that agricultural AI robots will change our interaction and views on food, nutrition, and produce. ${ }^{9}$ The widescale incorporation of robots on the farm might drive the view that our food is a product of our ingenuity, science, and abilities, with much less care for the ecological landscapes that allow us to survive in the first place. There is the potential that agricultural robots will change our relationship to food and farming landscapes because robots may change our well-being derived from food and farming landscapes, which what was once seen as 'nature' becomes infiltrated with 'unnatural' robots and machines.

In closing this argumentation, we want to suggest that next to impacts on the environment and animals, ethics of AI robots for agri-food should also be concerned with the theme of employment. The ethical concerns around employment are one of the most immediate issues that will be faced by agricultural AI robots in the coming years. There may be a tension between where AI robots may be most beneficial, in terms of greater output and productivity, and where they may be most needed to accommodate a declining labor force. While there is a greater labor elasticity in many poorer countries to incorporate autonomation and AI robots, there is not necessarily the same issue of labor shortages or people not wanting to work in the agricultural sector. Whereas there is a much smaller labor elasticity in wealthier farming countries, these are typically the places where there is a dramatic decline in individuals taking up professions in the agri-food sector. Questions that should be addressed by ethics for robotics in agri-food should include what constitutes equitable and just transfer of agri-food AI robots within developing countries and how it should be realized. Providing affordable and inclusive education and development in these countries should be considered, which would allow the population to upskill and improve the industry and their country's economic growth, while transferring jobs to these highly skilled and much sought-after employment opportunities for the community. Dialog could provide more insight into the concerns and fears of farmers surrounding agricultural AI robots to foster responsible and innovative implementation of these technologies on the farm. The question should be answered how respectful and

\footnotetext{
9 Thank you to one of the anonymous reviewers for providing this additional point.
} 
integrative exchanges can be realized, which will be about benefits from agricultural AI robots, while identifying and reducing many of the harmful and unwanted consequences of their use. Overall, ethics of AI robots for agri-food should address many questions concerning the good society, which produces food in a sustainable manner, and whether and how robots can contribute to it. (Table 2).

These issues have no straightforward solution and merit further research. The purpose of this paper was to provide an overview over current themes discussed in the ethics of AI robots' literature and identify whether and how these questions are relevant for the development of AI robots for agrifood. We have identified gaps in the debate and formulated questions that allow to progress from here in future research.

Acknowledgements We thank Aneesh Chauhan, Ard Nieuwenhuizen, Kees Lokhorst and Wijbrand Ouweltjes for commenting on earlier drafts of the paper.

Funding The funding that lead to this publication stems from two projects. That is the KB project on Autonomous Collaborative Robots (grant number KB-38-001-005, part of Data Driven High Tech programme) and the $\mathrm{H} 2020$ funded agROBOfood project (grant number 825395).

\section{Declarations}

Conflict of interest The authors declare that they have no conflicting interests.

Open Access This article is licensed under a Creative Commons Attribution 4.0 International License, which permits use, sharing, adaptation, distribution and reproduction in any medium or format, as long as you give appropriate credit to the original author(s) and the source, provide a link to the Creative Commons licence, and indicate if changes were made. The images or other third party material in this article are included in the article's Creative Commons licence, unless indicated otherwise in a credit line to the material. If material is not included in the article's Creative Commons licence and your intended use is not permitted by statutory regulation or exceeds the permitted use, you will need to obtain permission directly from the copyright holder. To view a copy of this licence, visit http://creativecommons.org/licenses/by/4.0/.

\section{References}

1. AWTI: Adviesraad voor Wetenschap, Technologie en Innovatie.: Klaar voor de toekomst? Naar een brede strategie voor ICT, ISBN: 9789077005736, (2015)

2. Allen, C., Varner, G., Zinser, J.: Prolegomena to any future artificial moral agent. J. Exp. Theor. Artif. Intell. 12(3), 251-261 (2000)

3. Allen, C., Wallach, W., Smit, I.: Why machine ethics? IEEE Intell. Syst. 21(4), 12-17 (2006)

4. Al-Razgan, M., AlFallaj, L.F., AlSarhani, N.S., AlOmair, H.W.: Systematic review of robotics use since 2005. Internat. J. Mech. Eng. Robotics Res. 5, 129 (2016)

5. Anderson, M., Anderson, S.L.: Toward ensuring ethical behavior from autonomous systems: a case-supported principle-based paradigm. Indust. Robot. An Internat. J. (2015)
6. Arkin, R.C., Ulam, P., Wagner, A.R.: Moral decision making in autonomous systems: enforcement, moral emotions, dignity, trust, and deception. Proc. IEEE 100(3), 571-589 (2011)

7. Arnold, T., Scheutz, M.: Against the moral Turing test: accountable design and the moral reasoning of autonomous systems. Ethics Inf. Technol. 18(2), 103-115 (2016)

8. Asaro, P.: What should we want from a robot ethic? Internat. Rev. Inform. Ethics 6(12), 9-16 (2006)

9. Autor, D.H.: Skills, education, and the rise of earnings inequality among the "other 99 percent." Sci. Am. Assoc. Adv. Sci. (2014). https://doi.org/10.1126/science.1251868

10. Basu, S., Omotubora, A., Beeson, M., Fox, C.: Legal framework for small autonomous agricultural robots. AI Soc. 35(1), 113-134 (2020)

11. Bendel, O.: Considerations about the relationship between animal and machine ethics. AI Soc. 31(1), 103-108 (2016)

12. Bertolaso, M., Rocchi, M.: Specifically human: human work and care in the age of machines. Bus. Ethics: European Rev. (2019)

13. Birhane, A., van Dijk, J.: Robot Rights? Let's talk about human welfare instead. in: proceedings of the AAAI/ACM Conference on AI, Ethics, and Society (pp. 207-213), (2020)

14 Bos, J., Munnichs, G.: Digitalisering van dieren Verkenning. Precision livestock farming. Rathenau Instituut (2016)

15. Bouzembrak, Y., Klüche, M., Gavai, A., Marvin, H.J.P.: Internet of Things in food safety: literature review and a bibliometric analysis. Trends Food Sci. Technol. 94, 54-64 (2019)

16. Briggs, G., Scheutz, M.: How robots can affect human behavior: Investigating the effects of robotic displays of protest and distress. Int. J. Soc. Robot. 6(3), 343-355 (2014)

17. Bryson, J.: Robots should be slaves. In: Wilks, Y. (ed.) Close engagements with artificial companions: Key social, psychological, ethical and design issues, pp. 63-74. John Benjamins Publishing (2010)

18. Bryson, J.: Patiency is not a virtue: AI and the design of ethical systems. AAAI Spring Symposium Series. Ethical and Moral Considerations in Non-Human Agents. http://www.aaai.org/ocs/ index.php/SSS/SSS16/paper/view/12686. (2016)

19. Brynjolfsson, E., McAfee, A.: Race against the machine: how the digital revolution is accelerating innovation, driving productivity, and irreversibly transforming employment and the economy. Brynjolfsson and McAfee. (2011)

20. Bunge, J.: Agricultural giants teach computers to farm. In The Wall Street Journal https://www.wsj.com/articles/leaf-recog nition-technology-agriculture-digs-into-artificial-intelligence1505300400. (2017)

21. Carbonell, I.: The ethics of big data in big agriculture. Internet Policy Rev. 5(1) (2016)

22. J. Chisholm.: What is Co-Design? http://designforeurope.eu/ what-co-design. (2018).

23. Coeckelbergh, M.: Robot rights? Towards a social-relational justification of moral consideration. Ethics Inf. Technol. 12(3), 209-221 (2010)

24. Coeckelbergh, M.: Health care, capabilities, and AI assistive technologies. Ethical Theory Moral Pract 13(2), 181-190 (2010)

25. Coleman, K.G.: Android arete: toward a virtue ethic for computational agents. Ethics Inf. Technol. 3(4), 247-265 (2001)

26. COMEST Report on Robotics Ethics (UNESCO, 2017); http:// unesdoc.unesco.org/images/0025/002539/253952E.pdf

27. Crnkovic, G.D., Çürüklü, B.: Robots: ethical by design. Ethics Inf. Technol. 14(1), 61-71 (2012)

28. Danaher, J.: The rise of the robots and the crisis of moral patiency. AI Soc. 34, 129-136 (2019)

29. Danaher, J.: Welcoming robots into the moral circle: a defence of ethical behaviourism. Sci. Eng. Ethics 26(4), 2023-2049 (2020) 
30. Donovan, A.: Robots that are invading the agriculture industry, interesting engineering, (2018). https://interestingengineeri ng.com/9-robots-that-are-invading-the-agriculture-industry (Accessed 2 Feb 2021)

31. Darling, K.: Extending legal protection to social robots. IEEE Spectrum. (2012). http://spectrum.ieee.org/automaton/robotics/ artificial-intelligence/extending-legal-protection-to-social-robots. (Accessed 2 Feb 2021)

32. Darling, K.: Extending legal protection to social robots: The effects of anthropomophism, empathy, and violent behavior toward robotic objects. In: Calo, R., Froomkin, A.M., Kerr, I. (eds.) Robot law, pp. 213-231. Edward Elgar (2016)

33. Daum, T.: Farm robots: ecological utopia or dystopia? Trends Ecol. Evol. 36(9), 774-777 (2021)

34. Dhamija, P., Bag, S.: Role of artificial intelligence in operations environment: a review and bibliometric analysis. TQM J. 32(4) (2020)

35. Driessen, C., Heutinck, L.F.: Cows desiring to be milked? Milking robots and the co-evolution of ethics and technology on Dutch dairy farms. Agric. Hum. Values 32(1), 3-20 (2015)

36. Duckett, T., Pearson, S., Blackmore, S., Grieve, B., Chen, W.H., Cielniak, G., From, P.: Agricultural robotics: the future of robotic agriculture. arXiv preprint. (2018) (Accessed 2 Feb 2021)

37. European Commission 2020. White paper on artificial intelligence - A European approach to excellence and trust. https://ec.europa. eu/info/sites/info/files/commission-white-paper-artificial-intel ligence-feb2020_en.pdf (Accessed 2 Feb 2021)

38. Frey, C.B., Osborne, M.A.: The future of employment: How susceptible are jobs to computerisation? Technol. Forecast. Soc. Chang. 114, 254-280 (2017)

39. Gerdes, A., Øhrstrøm, P.: Issues in robot ethics seen through the lens of a moral Turing test. J. Inf. Commun. Ethics Soc. 13(2), 98-109 (2015)

40. Goertzel, B.: Thoughts on AI morality. Dynamical Psychol. An Internat. Interdisciplinary J. Complex Mental Proc. (2002) http:// www.goertzel.org/dynapsyc/2002/AIMorality.htm. (Accessed 2 Feb 2021)

41. Gunkel, D.J.: The other question: can and should robots have rights? Ethics Inf. Technol. 20(2), 87-99 (2018)

42 Gunkel, D.J.: Thinking otherwise: philosophy, communication, technology. Purdue University Press (2007)

43. Gunkel, D.J.: The machine question: Critical perspectives on AI, robots, and ethics. MIT Press (2012)

44. Holloway, L.: Subjecting cows to robots: farming technologies and the making of animal subjects. Environ. Plan. D Soc. Space 25, 1041-1060 (2007)

45. Hutson, S., Lim, S.L., Bentley, P.J., Bianchi-Berthouze, N., Bowling, A.: Investigating the suitability of social robots for the wellbeing of the elderly. In: International Conference on Affective Computing and Intelligent Interaction (pp. 578-587). Springer. (2011)

46. Johnson, D.G.: Computer systems: moral entities but not moral agents. Ethics Inf. Technol. 8(4), 195-204 (2006)

47. Kool, L., Van Est, R.: Kansen en bedreigingen: negen perspectieven op werken in de robotsamenleving. De Robot de Baas $\mathbf{1}$, 49-67 (2015)

48. Levinas, E.: Totality and infinity: an essay on exteriority (A Lingis, Trans). Duquesne University (1969)

49. McGrath, J., Gupta, A.: Writing a moral code: algorithms for ethical reasoning by humans and machines. Religions 9(8), 240 (2018)

50. MacDorman, K.F., Ishiguro, H.: The uncanny advantage of using androids in social and cognitive science research. Interact. Stud. 7, 297-337 (2006)
51. MacDorman, K.F., Srinivas, P., Patel, H.: The uncanny valley does not interfere with level 1 visual perspective taking. Comput. Hum. Behav. 29(4), 1671-1685 (2013)

52. Marinoudi, V., Sørensen, C.G., Pearson, S., Bochtis, D.: Robotics and labour in agriculture. A context consideration. Biosyst. Eng. 184, 111-121 (2019)

53. Mavroforou, A., Michalodimitrakis, E., Hatzitheofilou, C., Giannoukas, A.: Legal and ethical issues in robotic surgery. Int. Angiol. 29(1), 75 (2010)

54. Mitka, E.: Strategy for safer agricultural robots. Economics World 6(6), 472-481 (2018)

55. Moon, A., Danielson, P., Van der Loos, H.M.: Survey-based discussions on morally contentious applications of interactive robotics. Int. J. Soc. Robot. 4(1), 77-96 (2012)

56. NASA. How NASA and John Deere helped tractors drive themselves. NASA. (2018). https://www.nasa.gov/feature/directorates/ spacetech/spinof/john_deere. (Accessed 2 Feb 2021)

57. Niknejad, N., Ismail, W., Bahari, M., Hendradi, R., Salleh, A.Z.: Mapping the research trends on blockchain technology in food and agriculture industry: a bibliometric analysis. Environ. Technol Innov. 21, 101272 (2021)

58. Ojha, S., Williams, M.A., Johnston, B.: The essence of ethical reasoning in robot-emotion processing. Int. J. Soc. Robot. 10(2), 211-223 (2018)

59. O’Sullivan, S., Nevejans, N., Allen, C., Blyth, A., Leonard, S., Pagallo, U., Ashrafian, H.: Legal, regulatory, and ethical frameworks for development of standards in artificial intelligence (AI) and autonomous robotic surgery. Internat. J. Med. Robot. Comput. Assist. Surg. 15(1), e1968 (2019)

60. Pearson, Y., Borenstein, J.: Creating "companions" for children: the ethics of designing esthetic features for robots. AI Soc. 29(1), 23-31 (2014)

61. Pekkeriet, E., Splinter, G.: Arbeid in de toekomst: Inzicht in arbeid en goed werkgeverschap in de tuinbouw (No 2020-002). Wageningen Economic Research (2020)

62. Precision, H.: (2018) How BASF uses drones to measure turf health. PrecisionHawk. https://www.precisionhawk.com/media/ topic/how-basf-uses-drones-to-measure-turf-health/. (Accessed 2 Feb 2021)

63. Scheutz, M., Arnold, T.: Feats without heroes: norms, means, and ideal robotic action. Front. Robot. AI 3, 32 (2016)

64. Robertson, L.J., Abbas, R., Alici, G., Munoz, A., Michael, K.: Engineering-based design methodology for embedding ethics in autonomous robots. Proc. IEEE 107(3), 582-599 (2019)

65. Ruiz-Real, J.L., Uribe-Toril, J., Torres, A.J.A., de Pablo, V.J.: A Look at the past, present and future research trends of artificial intelligence in agriculture. Agronomy 10(11), 1839 (2020)

66. Ryan, M.: Ethics of using AI and big data in agriculture: the case of a large agriculture multinational. ORBIT J, 2(2) (2019)

67. Ryan, M.: Agricultural big data analytics and the ethics of power. J. Agric. Environ. Ethics 33(1), 49-69 (2020)

68. Ryan, M.: In AI we trust: ethics, artificial intelligence, and reliability. Sci. Eng. Ethics 26, 2749-2767 (2020)

69. Sarma, G., Hay, N.: Mammalian value systems. Informatica 41(3) (2017)

70. Sharkey, N., Sharkey, A.: Robotic surgery: on the cutting edge of ethics. Computer 46(1), 56-64 (2012)

71. Singh, S., Haneef, F., Kumar, S., Ongsakul, V.: "Internet of things and agriculture relationship: a bibliometric analysis". J. Global Bus. Adv. 13(5) (2021)

72. Smith, M.J.: Getting value from artificial intelligence in agriculture. Animal Prod. Sci. 60(1), 46-54 (2020)

73. Sparrow, R., Mark, H.: 'Robots in agriculture: prospects, impacts, ethics, and policy'. precision agriculture, 1-16 (2020) 
74. Sparrow, R., Howard, M.: When human beings are like drunk robots: driverless vehicles, ethics, and the future of transport. Trans Res Part C: Emerging Technol 80, 206-215 (2017)

75. Takayama, L., Ju, W., Nass, C.: Beyond dirty, dangerous, and dull. What Everyday People Think Robots Should Do. In: Proc Human-Robot Interact. ACM/IEEE, Amsterdam, NL (2008)

76. Tonkens, R.: A challenge for machine ethics. Mind. Mach. 19(3), 421 (2009)

77. Torrance, S.: Ethics and consciousness in artificial agents. AI Soc. 22(4), 495-521 (2008)

78. Torresen, J.: A review of future and ethical perspectives of robotics and AI. Front. Robot. AI 4, 75 (2018)

79. Turkle, S.: Alone together: Why we expect more from technology and less from each other. Basic Books (2012)

80. Van der Burg, S., Bogaardt, M.J., Wolfert, S.: Ethics of smart farming: Current questions and directions for responsible innovation towards the future. NJAS-Wageningen J. Life Sci. 90, 100289 (2019)

81. Van der Burg, S., Wiseman, L., Krkeljas, J.: Trust in farm data sharing: reflections on the EU code of conduct for agricultural data sharing. Ethics Inform. Technol. 1-14 (2020)
82. Van Est, R.; Kools, L.: Working on the Robot Society. Visions and insights from science concerning the relationship between technology and employment, rathenau institute: The Hague. (2015).

83. Van Est, R., Gerritsen, J.B.A., with the assistance of Kool, L.: Human rights in the robot age: challenges arising from the use of robotics, artificial intelligence, and virtual and augmented reality - expert report written for the committee on culture, science, education and media of the parliamentary assembly of the Council of Europe (PACE), The Hague: Rathenau Instituut, (2017)

84. van Wynsberghe, A., Donhauser, J.: The dawning of the ethics of environmental robots. Sci. Eng. Ethics 24(6), 1777-1800 (2018)

85. Visser, F.S., Stappers, P.J., van der Lugt, R., Sanders, E.B.-N.: Contextmapping: experiences from practice. CoDesign 1(2), 119-149 (2005)

86. Wallach, W., Allen, C.: Moral machines: teaching robots right from wrong. Oxford University Press (2008)

Publisher's Note Springer Nature remains neutral with regard to jurisdictional claims in published maps and institutional affiliations. 